\title{
Erratum - Cadaveric Dissection of the Axillary Nerve: An Investigation of Extra-Muscular and Intra-Muscular Branching Patterns
}

\author{
[Journal of Hand Surgery Asian-Pacific Volume 2018;23(4):533-538] \\ Pratik Rastogi, David A. Stewart, Richard D. Lawson, \\ Dominique M. Tremblay, Belinda J. Smith, Michael A. Tonkin \\ Department of Hand Surgery and Peripheral Nerve Surgery, \\ Royal North Shore Hospital (Northern Sydney Local Health District), University of Sydney, Sydney, Australia
}

In the previously published version of this article, there were errors in Figures 1, 3 and their legends. Their corrected versions are presented below:

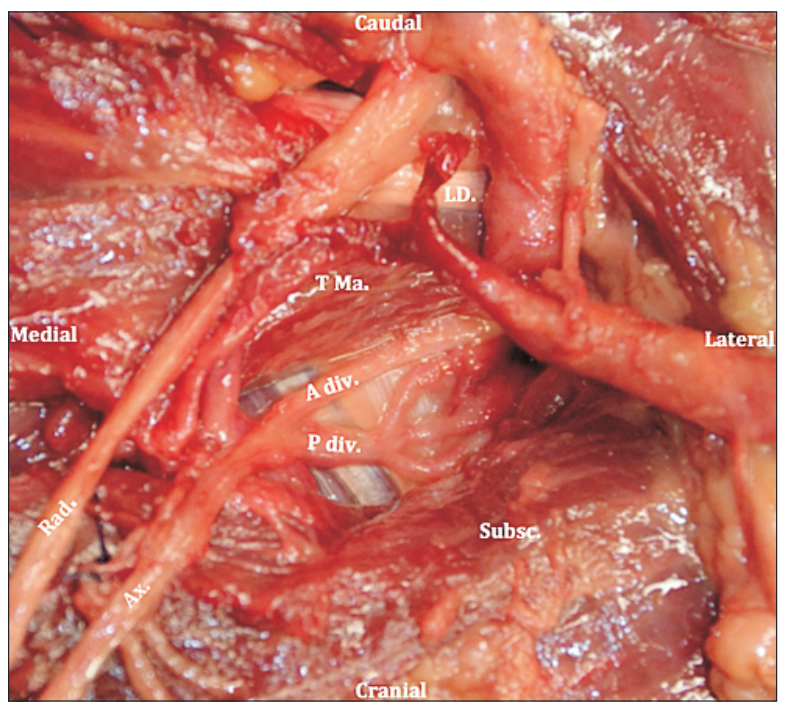

Fig. 1. Bifurcation of the axillary nerve into its anterior (A div.) and posterior division ( $\mathrm{P}$ div.) within the quadrangular space of right shoulder cadaveric specimen. The posterior division is located more superiorly within the quadrangular space and noted to trifurcate into the motor branches (posterior deltoid and teres minor) and sensory brachial cutaneous branch.

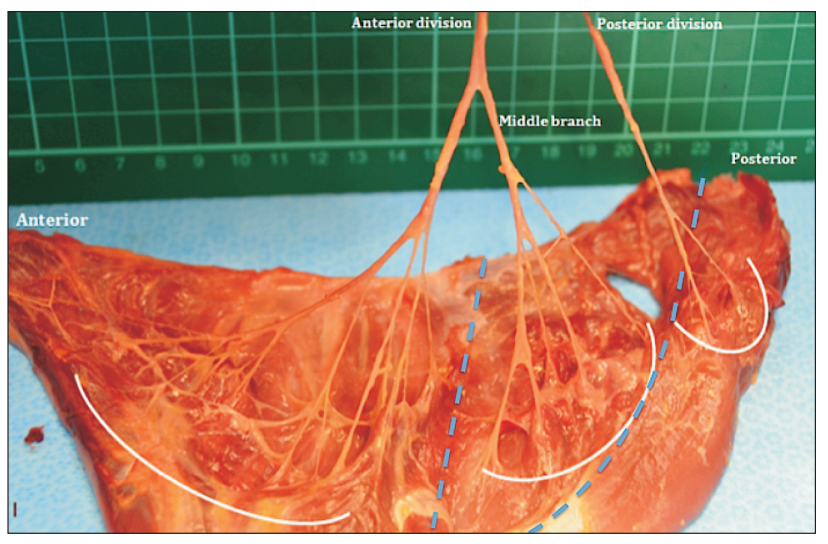

Fig. 3. Intramuscular dissection of axillary nerve. The middle branch from anterior division, anterior division proper and posterior division of the axillary nerve are identified. Arcs indicate arborizing subdivisions of nerve branches. The blue dashed lines schematically indicate the divisions between adjacent deltoid segments by regional innervation. 


\title{
IFSSH Newsletter February 2019
}

\author{
XIVth IFSSH - XIth IFSHT Congress - Berlin, Germany \\ 17-21 June, 2019 \\ www.ifssh-ifsht2019.com \\ XVth IFSSH - XIIth IFSHT Congress - London, United Kingdom \\ 27th June - 1st July, 2022 \\ www.ifssh2022.london
}

\section{MESSAGE FROM THE SECRETARY-GENERAL: $14^{\text {th }}$ IFSSH \& $11^{\text {th }}$ IFSHT Triennial Congress, Berlin - June 17-21, 2019}

The main scientific event of the IFSSH calendar, the Triennial Congress, is just three months away. We are pleased to report the local organizing committee in Berlin is working feverishly to organize an outstanding meeting. Recent developments include:

\section{Registration}

○ "EarlyBird" registration is available until $28^{\text {th }}$ February 2019. http://ifssh-ifsht2019.com/registration/.

- A new reduced registration status, "Doctor-inTraining" has been introduced. Full details are on the registration webpage.

- Congress assistance grants are available for those from low income or developing nations, courtesy of the IFSSH Educational Sponsorship program. Applications close on $28^{\text {th }}$ February, 2019 and will then be reviewed by the Congress organizers. Please promote this opportunity for financial support to colleagues who may wish to attend but require financial assistance to do so. http://ifsshifsht2019.com/ifssh-congress-assistance-grants/.

\section{Scientific Program}

○ Professor Steven Hovius from Rotterdam will deliver the Swanson Lecture, entitled "Challenges!?"

$\circ$ A total of over 1800 hand surgery and hand therapy abstracts were submitted to the program committee. The daunting task of abstract review and selection was accomplished by 200 renowned surgeons and therapists from a broad geographic distribution. Our sincere thanks go to all those involved. $\circ$ The first day of the Congress, Monday, June $17^{\text {th }}$ will be "Educational Monday" and will offer focused presentations on a variety of topics such as nerve surgery, the treatment of scaphoid and distal radius fractures, prosthetics, orthotic fabrication and wrist arthroscopy. Please watch the IFSSH Congress website for more information regarding "Educational Monday."

- Live internet streaming of the events taking place in the main hall will be available on the Congress Website.

\section{Social Program}

○ The Welcome Cocktail will be held immediately after the Opening Ceremony on Monday in the CityCube.

○ "Berlin Night" will be held on Tuesday, June 18 in the "Kühlhaus", a cold storage facility dating back to 1901 which has been restored to preserve its neo-gothic architecture typical of northern Germany. Please stay tuned as more information will be posted on the Congress website for details regarding what will definitely be a very "cool" evening.

- The Congress Dinner \& Party will take place Thursday evening, June 19, in the beautiful Ritz Carlton Ballroom.

\section{Travel}

Berlin is an extraordinary city with a rich history and a dizzying array of culinary, architectural and cultural activities, as well as an unapparelled night life/club scene. To help you plan your "extra-curricular" activities while in Berlin the organizing committee suggests you explore the following websites:

○ Plan your travel http://ifssh-ifsht2019.com/travel/ 
and accommodation http://ifssh-ifsht2019.com/accommodation/.

$\circ$ Destination Europe and Germany http://ifsshifsht2019.com/destinations/.

- Practical information concerning your visit in Germany http://ifssh-ifsht2019.com/practical-information/.

- Berlin by Night - young surgeons' recommendations http://ifssh-ifsht2019.com/berlin-by-night/.

- Recommendations for accompanying persons http://ifssh-ifsht2019.com/tours-sightseeing/.

The Executive Committee has been in constant contact with the organizing committee and there is no doubt the IFSSH \& IFSHT Congress will be extraordinary in every way. The organizing committee has spared no effort to assure the highest level of scientific information will be presented. They have also made a concerted effort to make the Congress affordable.

In just three months the IFSSH/IFSHT "families" will meet in Berlin and I hope you will not miss this opportunity to renew old friendships, make new friends and exchange knowledge, all while enjoying one of Europe's most exciting cities.

Best wishes to all from the Executive Committee

We hope to see you in Berlin!

Best regards,

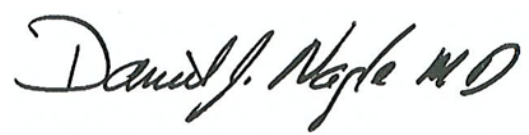

Daniel J Nagle, M.D. Secretary-General, IFSSH

Email: secretary@ifssh.info

\section{IFSSH Delegates' Council Meeting}

The 2019 IFSSH Delegates' Council Meeting will be held during the Berlin congress. Full details will be sent to the society delegates in the near future.

A number of important items will be discussed and decided at this meeting, including the election of the 2019-2022 IFSSH Executive Committee, the allocation of the 2025 IFSSH Triennial Congress, and a review of the by-laws.

We hope to see the participation of a representative of every IFSSH member society at this Council Meeting.

\section{IFSSH TRIENNIAL CONGRESS HOST SOCIETY}

The 2025 IFSSH Triennial Congress is allocated to The Americas under the geographic rotation system. The IFSSH Executive Committee has called for bids to host this meeting. Full guidelines are available on the IFSSH website: http://ifssh.info/guidelines.php.

Submissions should be forwarded to the Secretary General (administration@ifssh.info) by 17 $7^{\text {th }}$ March 2019. The same documentation must be sent to each member country delegate and IFSHT representative for evaluation. This distribution is the responsibility of the nominating society. The contact details of all societies are on the IFSSH website: http://ifssh.info/member_nation.php.

Each bidding society is expected to provide a brief presentation during the 2019 IFSSH Delegates' Council and the 2025 host will be chosen by a majority vote of the delegates.

\section{EDUCATIONAL SPONSORSHIP}

The IFSSH Executive Committee and Committee for Educational Sponsorship have recently provided two grants:

○ Sponsorship has been awarded to the 2nd International Symposium on Surgery of the Spastic Upper Limb. This symposium will be held in Venice, Italy on 5th-6th April, 2019. The organisers have created a reduced registration fee category which is being underwritten by IFSSH funds, for those participants from developing regions of the world. Full details are available via the congress website: http://www.symposium-spastic-hand.com/en/.

- Ongoing IFSHT activities have again been sponsored. These include the IFSSH/IFSHT Triennial Travel Grant, the Evelyn Mackin Triennial Award and the IFSHT/IFSSH International Teaching Grant - https://www.ifsht.org/page/awards-grants. We congratulate the IFSHT on their ongoing support of education amongst therapists worldwide. Two reports from recent recipients will be published in the IFSSH ezine, demonstrating the reach of their expertise and assistance to under-served communities.

Full details on the Educational Sponsorship application process are available via http://ifssh.info/educational_sponsorship.php. 


\section{National and Regional Hand Surgery Meetings}

Please see announcements in the Ezine and IFSSH website.

Please remember to follow us on Twitter for regular updates: @IFSSHand 